\title{
Representações do discurso médico-eugênico sobre a descendência: a eugenia mendelista nas teses doutorais da Faculdade de Medicina $e$ Cirurgia de São Paulo na década de 1920' Representations of the medical-eugenic discourse about progeny: mendelist eugenics in the doctoral theses of the Medicine and Surgery College of São Paulo [Faculdade de Medicina e Cirurgia de São Paulo] in the 1920s
}

\section{Beatriz Lopes Porto Verzolla}

Universidade de São Paulo. Faculdade de Medicina. Departamento de Medicina Preventiva. São Paulo, SP, Brasil.

E-mail: bia.verzollaœgmail.com

\section{André Mota}

Universidade de São Paulo. Faculdade de Medicina. Departamento de Medicina Preventiva. São Paulo, SP, Brasil.

E-mail: andremotaıßœgmail.com

\section{Correspondência}

Beatriz Lopes Porto Verzolla

Av. Dr. Arnaldo, 455, 2 andar. São Paulo, SP, Brasil. CEP oI246-903.

\section{Resumo}

A eugenia representou um movimento de grande repercussão a partir do final do século XIX e pretendia o melhoramento e aprimoramento da espécie humana, abrangendo ações de educação e de restrições à reprodução, contribuindo para a construção da ordem e da civilidade, baseada no progresso e na superioridade moral e física dos indivíduos. Este artigo visa apresentar e discutir elementos extraídos das teses doutorais da Faculdade de Medicina da Universidade de São Paulo na década de 1920, especificamente relacionados ao tema da eugenia mendelista, sob a ótica da produção discente da época. 0 período escolhido representa um momento de grande influência da medicina na sociedade, em ações de controle e normatização dos indivíduos, influenciadas pelas teorias eugênicas. As teses doutorais representam o início da produção discente da Faculdade e contêm influências das teorias em voga no período - teorias evolucionistas, positivistas e eugenistas. Foram selecionadas para apresentação neste artigo oito teses doutorais, analisadas a partir do conceito de representações como técnica de leitura de documentos. Nas teses analisadas, pôde-se observar uma preocupação dos autores com a formação de uma descendência eugênica, defendendo o estabelecimento de medidas como restrição de

1 Este artigo foi produzido a partir de pesquisa realizada para dissertação de mestrado em Medicina Preventiva: Medicina, saúde e edu cação: o discurso médico-eugênico nas teses doutorais da Faculdade de Medicina e Cirurgia de São Paulo entre 1920 e 1939. 
casamentos, exame médico pré-nupcial e, em alguns casos, esterilização compulsória.

Palavras-chave: Eugenia; Teses Doutorais; História da Medicina.

\section{Abstract}

Eugenics represented a movement of great repercussion by the end of $19^{\text {th }}$ century, which intended to improve and enhance human species, including actions of education and restrictions to reproduction, contributing to the foundation of order and civility, based on progress and on moral and physical superiority of individuals. This article aims to present and discuss elements extracted from doctoral theses of the Medicine College of the University of São Paulo (Faculdade de Medicina da Universidade de São Paulo) in the 1920s, specifically related to the theme of mendelist eugenics from the point of view of that period's scientific production. The chosen span represents a moment of great influence of medicine in society, because of actions of control and normalization of individuals, influenced by eugenic theories. The doctoral theses represent the beginning of the College's student production and contain influences from theories in vogue of the period - evolutionist, positivist and eugenic theories. Eight doctoral theses were selected for presentation in this article, and they were analyzed from the concept of representation as document reading technique. In these theses, one can observe the concern of the authors with the formation of eugenic descent, defending the establishment of measures such as restriction to marriages, prenuptial medical examination and, in some cases, compulsory sterilization.

Keywords: Eugenics; Doctoral Thesis; History of Medicine.

\section{Introdução}

O termo eugenia - do grego eugenes, "bem-nascido" - foi empregado pelo inglês Francis Galton pela primeira vez em 1883, em seu livro Inquiries into human faculty and its development, sob o enfoque da divulgação da reprodução humana controlada como potencial alternativa para o aperfeiçoamento da espécie. Em suas origens, a eugenia representava a aplicação de práticas de melhoramento e aprimoramento da espécie humana, trazendo influências dos conceitos biológicos de seleção natural, aptidão, meio ambiente e da teoria evolucionista de Charles Darwin, transferindo-os do mundo natural e aplicando-os à sociedade humana, o que forneceu grande embasamento científico às concepções eugênicas (Black, 2003; Galton, 1876; Gould, 1991; Kevles, 1985; Marques, 1994; Mota, 2003; Stepan, 2005).

Para Stepan (2005), a eugenia estabeleceu-se como movimento científico que se baseou nos entendimentos novos das leis da hereditariedade humana e como movimento social, envolvendo propostas que asseguraram a melhoria da composição hereditária da sociedade, encorajando a reprodução dos superiores e desencorajando a dos inferiores e indesejados. Quanto aos aspectos práticos, a eugenia era favorável à administração científica da composição hereditária da espécie humana, introduzindo novas ideias sociais e políticas inovadoras. A eugenia como ciência do aprimoramento racial abordava tal questão como melhoria genética da raça humana, porém os eugenistas interessavam-se por parcelas específicas da população humana, dividida em raças distintas e desiguais (Schwarcz, 1993; Stepan, 2005). Sobre a definição de eugenia, Barbosa (1917), aponta:

Eugenia, s.f. [do gr. eugeneia, nobreza de nascimento] = sciencia que estuda as causas e influencias que, por via de herança, podem melhorar ou prejudicar as qualidades naturais fisicas ou psiquicas do homem: a eugeni'a tem por fim a geração de individuos normais e perfeitos, e a repressão da progenie defeituosa e degenerada, empregando para isso os conhecimentos da hereditariedade e da sociologia (Barbosa, 1917, p. 245). 
No início do século XX, especialmente após a morte de Galton, suas ideias originais deram lugar à aplicação de sua teoria inicial em medidas de segregação, deportação, esterilização e extermínio, notadamente nos Estados Unidos. Os ideais eugênicos encontraram aceitação no país pelos escalões mais altos da sociedade, que temiam o caos demográfico que assolava a nação, devido às grandes taxas de imigração e à miscigenação racial e étnica. A difusão do racismo, do preconceito de classe e do ódio, somada às teorias da hereditariedade da criminalidade e dos custos econômicos dos "indesejáveis" à sociedade favoreceram um ambiente fértil para o campo da eugenia (Black, 2003; Stepan, 2005).

Os ideais eugênicos abrangiam, principalmente, duas teorias distintas: a eugenia positiva (lamarckista) e a eugenia negativa (mendelista). A eugenia positiva, inspirada nas teorias lamarckistas de evolução das espécies, defendia ser possível a modificação de traços hereditários por meio de ações ambientais, como higiene e educação, encontrando campo médico fundamentalmente na área de saúde da infância, com destaque para a puericultura. Dessa forma, mudanças no ambiente provocariam modificações nas necessidades dos organismos, que, consequentemente, levariam a adaptações. A eugenia negativa baseava-se nas teorias mendelistas - que resultaram nos princípios dos estudos sobre genética - e defendia que os caracteres seriam transmitidos por hereditariedade aos descendentes, não sendo possível que houvesse alterações hereditárias a partir de ações externas, tendo como uma de suas propostas a esterilização dos chamados "inferiores", para impedir a propagação de uma raça impura (Kevles, 1999; Marques, 1994; Mota, 2003, 2012; Novaes, 2009).

No Brasil, o contexto social que favoreceu o estabelecimento da eugenia está relacionado com o colapso final de uma sociedade escravocrata, em 1888, e a abertura do país à imigração europeia. Em termos políticos, encontrou a queda da monarquia e o advento da república em 1889 e, economicamente, o crescente envolvimento do país no sistema capitalista mundial, em posição de dependência, como fornecedor de café (Stepan, 2005). Em um contexto de crescentes mudanças, fazia-se necessário restabelecer a ordem social, contendo a insatisfação da população e promovendo a organização das cidades, em busca de uma sociedade que se desenvolvesse dentro dos modos capitalistas de produção. Aprimoraram-se as medidas de saneamento das cidades, com a limpeza e ordem das ruas e casas e o abastecimento de água e esgoto, assim como o controle das epidemias (Bertucci, 1997; Mota, 2005).

A eugenia foi recebida no Brasil, e especialmente em São Paulo, como um termo médico, sendo introduzida nas diferentes especialidades e discutida pela corporação médica como tecnologia científica a ser implementada, desde estudos obstétricos às ações dos cirurgiões, das práticas sanitárias às experiências psiquiátricas (Mota, 2012). Contudo, as práticas eugênicas eram interpretadas e praticadas de formas diversas ou opostas, defendendo ações ambientais na regeneração do homem - eugenia lamarckista ou ações baseadas na genética e na hereditariedade para a melhoria racial - eugenia mendelista (Bonfim; Kuhlmann Junior, 2014; Mota, 2012):

não se pode afirmar que o movimento eugênico brasileiro constituiu um campo de debate homogêneo, produzindo consensos quanto à definição de seus fundamentos e aplicações sociais. Difícil é dizer qual era o significado preciso dessa ciência entre os nossos eugenistas, dada a diversidade de perspectivas presentes nessa construção (Bonfim; Kuhlmann Junior, 2014, p. 4).

A eugenia mendelista ganhou destaque internacional, e também no Brasil, apesar de pouco difundido na literatura que os autores brasileiros tenham revelado afinidades com as medidas eugênicas mais restritivas, especialmente após a Segunda Guerra Mundial e o genocídio nazista, que exterminou milhões de pessoas consideradas inferiores. Mota (2012) afirma que se destacava no pensamento intelectual brasileiro uma concepção da eugenia lamarckista, porém havia espaço aberto para a recepção das teorias mendelistas, restritivas e esterilizadoras, defendidas notadamente no meio médico paulista e divulgadas em conferências e congressos. Um dos importantes meios de divulgação da eugenia entre a população paulista eram os concursos de eugenia, que selecionavam as crianças consideradas eugênicas, a partir da avaliação de características físicas 
e mentais, não apenas das próprias crianças, mas também de seus ascendentes, premiando aquelas consideradas perfeitas e sadias quanto à própria constituição e de seus antepassados (Kehl, 1929).

A eugenia mendelista apresentava como propostas maior controle governamental sobre os casamentos e sobre a reprodução, por meio de exames médicos pré-nupciais; controle das fontes de "degeneração", como o alcoolismo, as doenças venéreas e outros vícios sociais; restrições imigratórias de tipos indesejáveis; segregação e esterilização de pessoas consideradas débeis ou portadoras de taras nocivas à descendência. A propaganda eugênica mendelista era destinada, especialmente, às classes mais empobrecidas da população, tendo como alvo principal os negros, mulatos e mestiços, considerados pelos eugenistas como elementos inferiores (Mai; Angerami, 2006; Mota, 2005). Ainda como medida eugênica de seleção racial, a Lei brasileira, por meio do Decretolei $\mathrm{n}^{0} 528$, de 1890 , restringia o acesso de imigrantes asiáticos e africanos, condicionados à aprovação pelo Congresso Nacional, a fim de evitar a entrada de imigrantes considerados indesejáveis à composição racial do brasileiro (Brasil, 189ob).

Neste estudo, considera-se a eugenia como um movimento científico que encontrou respaldo de importantes intelectuais que legitimaram o movimento eugênico nos meios acadêmicos, embasando cientificamente suas teorias e proposições, que foram colocadas em prática de diferentes formas ao redor do mundo. $\mathrm{O}$ objetivo deste artigo consiste em apresentar e discutir elementos relacionados ao tema da eugenia mendelista (ou negativa), extraídos das teses doutorais da Faculdade de Medicina da Universidade de São Paulo na década de 1920, sob a ótica da produção discente do período.

\section{As teses doutorais da Faculdade de Medicina e Cirurgia de São Paulo²}

A criação da Faculdade de Medicina e Cirurgia de São Paulo, em 1912, foi permeada por intensas disputas políticas e institucionais e aconteceu em meio aos debates sobre a formação da população e o saneamento do país, diante da necessidade de uma nova organização social e econômica gerada pela crescente urbanização da cidade (Bertucci, 2013; Marinho, 2013; Mota, 2005). As tendências filosóficas e científicas disseminadas na época - teses positivistas, evolucionistas e eugenistas - foram apropriadas pelos intelectuais, dentre eles o primeiro diretor da Faculdade de Medicina e presidente da primeira Sociedade de Eugenia do Brasil, Arnaldo Vieira de Carvalho. Durante o período de 1916 a 1931, a Faculdade de Medicina passou por importantes transformações, a partir da presença da Fundação Rockefeller em sua estrutura acadêmica, no contexto de crescimento da influência norte-americana na economia e política do país. A instituição filantrópica mantinha acordos com a faculdade e priorizava o apoio a ações de Saúde Pública e ao ensino médico, considerando que a enfermidade seria a principal causa da pobreza e deveria ser combatida com instrumentos da ciência, civilização e progresso (Marinho; Mota, 2012; Marinho, 2013).

O título de médico era fornecido aos alunos que concluíssem o curso normal em ciências médicas, permitindo a habilitação para o exercício legal da profissão. A partir de 1918, o currículo do curso de Medicina passou a trazer como exigência a defesa de uma tese doutoral por parte dos alunos para a obtenção do título de doutor em medicina. Os alunos deveriam apresentar uma tese acerca de estudos pessoais de natureza técnica ou científica de livre escolha, devendo conter o máximo possível de documentações, fotografias, gráficos, estatísticas e informações bibliográficas. 0 tema das teses poderia ser escolhido pelos alunos, com ou sem auxílio dos professores, sua apresentação deveria seguir o padrão mínimo exigido pela faculdade, contando com um professor orientador e a tese final deveria ser defendida perante uma banca composta por professores do curso (São Paulo, 1932, 1935)³.

As teses doutorais refletem o início da produção discente do curso de Medicina da faculdade,

2 A Faculdade de Medicina e Cirurgia de São Paulo assumiu outras denominações ao longo do tempo, passando para Faculdade de Medicina de São Paulo - FMSP (1925-1934) e Faculdade de Medicina da Universidade de São Paulo - FMUSP (1934-atual). Neste artigo, optou-se por manter a denominação original da fundação da faculdade.

3 Para maiores informações acerca da produção das teses doutorais, consultar o acervo disponível de 1918 a 1969 no banco de dados bibliográficos da USP (Dedalus) e os Regulamentos da Faculdade de Medicina, disponíveis no Museu Histórico Prof. Carlos da Silva Lacaz. 
recebendo influências dos conteúdos acadêmicos ministrados ao longo do curso e passando pela aprovação dos professores, alinhados aos estudos e práticas científicas em voga no período estudado. Alguns dos autores das teses alcançaram outros tipos de publicações com seus estudos, como é o caso do Boletim de Eugenia ${ }^{4}$ e do Boletim do Instituto de Higiene ${ }^{5}$, periódicos que veiculavam temas referentes à eugenia, higiene e sanitarismo, e contavam com a colaboração de importantes intelectuais para divulgação de artigos ao meio acadêmico e à população em geral.

A produção das teses era direcionada, essencialmente, para leitores da comunidade acadêmica, podendo ultrapassar fronteiras institucionais e atingir a intelectualidade paulistana e brasileira de forma geral, contribuindo para a ampliação das representações sobre os conceitos e teorias abordados para medidas práticas, em uma identificação social entre os autores e seus leitores - muitas vezes a própria comunidade médica, correspondente a uma grande parcela da intelectualidade brasileira, que exercia influência sobre processos de normatização e até mesmo sobre a criação de leis.

A seleção das teses doutorais utilizadas na pesquisa foi realizada inicialmente a partir de um levantamento preliminar no Banco de Dados Bibliográficos da USP (Dedalus), utilizando o filtro de data, resultando em um quantitativo inicial de 593 títulos ${ }^{6}$. A seleção das teses foi realizada por meio de refinamento a partir dos títulos de interesse, sendo mantidos os que apresentavam menção direta ao termo "eugenia" e correlatos ("eugênico", "eugenista", "eugenismo"), bem como aqueles que continham termos relacionados de alguma forma aos conceitos e práticas médico-eugênicas do período, atingindo 73 títulos. Novos refinamentos foram feitos para seleção das teses a partir da leitura dos resumos e prefácios e, posteriormente, do texto integral, tendo a seleção final atingido 45 teses de interesse para análise.

Para a produção deste artigo, foram selecionadas oito teses para exposição dos conteúdos relacionados à temática abordada e ao período selecionado, por apresentarem maior relevância para o objetivo deste artigo (Tabela 1). A investigação do objeto deste estudo a partir da utilização de fontes documentais está metodologicamente pautada no conceito da lógica histórica (Thompson, 1981), considerando as articulações do objeto com o contexto socioeconômico, político e cultural. A técnica de leitura dos documentos baseia-se no conceito de representações, proposto por Chartier (1991), tendo como padrão de análise a identificação de identidades sociais na leitura a partir do estabelecimento de relações entre um objeto ausente e uma imagem presente e correspondente ao seu referente. Dessa forma, considera-se a construção do sentido das leituras um processo historicamente determinado, variando segundo o tempo, o lugar e as comunidades.

\section{A descendência em questão: sobre a transmissibilidade de taras hereditárias ${ }^{7}$ no discurso médico-eugênico}

A importância atribuída à eugenia na formação de indivíduos saudáveis, homogêneos e padronizados, aptos para o trabalho - e, para isto, suscetíveis a toda forma de controle - pode ser identificada nos apontamentos de diferentes autores das teses doutorais analisadas, ganhando destaque discussões acerca da seleção de grupos mais favoráveis a propagar seus genes às gerações futuras. Tal preocupação com a

\footnotetext{
4 Periódico editado por Renato Kehl, publicado de 1929 a 1933, cujo objetivo era auxiliar na campanha em prol da eugenia, sendo direcionado à intelectualidade brasileira e aos cidadãos preocupados com o destino da nação. Alguns exemplares podem ser consultados no acervo do Museu Histórico Prof. Carlos da Silva Lacaz.

5 Periódico publicado de 1919 a 1946, composto por artigos escritos pelos principais pesquisadores na área da Saúde Pública do Instituto de Higiene de São Paulo. 0 acervo digitalizado pode ser encontrado no Portal de Revistas da USP (https://goo.gl/U7h5Nr).

6 Devido à recente inserção das teses no banco de dados bibliográficos no período em que foi realizado o levantamento preliminar, os procedimentos de busca ainda eram restritos e passariam por processo de aperfeiçoamento, não sendo possível, à época, realizar o refinamento da pesquisa por área temática de produção das teses.

7 A utilização do termo "taras hereditárias" refere-se a uma teoria em voga entre os eugenistas do período, que defendia a transmissão hereditária de uma predisposição ao desenvolvimento de determinadas doenças e condições, mesmo na ausência de um agente etiológico transmitido hereditariamente, como no caso de uma tendência herdada para o desenvolvimento do alcoolismo e da criminalidade.
} 
descendência consistiu em um dos temas centrais das teorias discutidas no âmbito da eugenia mendelista (ou negativa), passando pela defesa do controle de casamentos e de políticas de esterilização compulsória para os considerados indesejáveis, a fim de evitar ou eliminar a procriação desses indivíduos, para que não gerassem uma prole de crianças disgênicas (Antunes, 1926; Guimarães Filho, 1926; Godoy, 1927; Monteleone, 1929, Ribas, 1927):

A Eugenia Negativa ou selêção eugenica da especie humana tem por finalidade a restrição do nacimento de individuos anormaes, tarados, inferiores, enfim, celulas geradas com estigmas degenerativos. Para a realização de seu objêtivo, a Eugenia Negativa propõi dois meios: o exame pré-nupcial obrigatorio e a esterilização humana dos máus procreadores (Godoy, 1927, p. 29).

As crianças eram consideradas centrais na elaboração de medidas e intervenções realizadas no âmbito da eugenia. A formação de indivíduos fortes e combativos para exercer sua força de trabalho no futuro era fundamental, o que justificava a preocupação dos eugenistas com os casamentos sadios e com a geração de uma prole saudável e apta para responder às expectativas da produção capitalista, assim como defende Godoy (1927), em sua tese Eugenia e seleção: "Porque é do berço, da criança, da eugenização das gerações futuras que surgirá o Brazil grande e sadio, respeitado e trabalhador, rico e alegre de amanhã!!” (Godoy, 1927, p. 11).

A empreitada eugenista buscava a perfeição da humanidade, seguindo padrões homogêneos de características físicas e comportamento e considerando condições de vida geradas por questões sociais sob as lentes da biologia. As medidas de controle sobre os casamentos e a reprodução configuravam-se, em última instância, em um controle direcionado sobre os corpos, como uma forma de controle prévia ao inculcamento de ideologias e, nas palavras de Foucault (1984), caracterizando o corpo como realidade biopolítica e a medicina como estratégia para sua efetivação.

Para Antunes (1926), em sua tese Eugenia e immigração, assim como as características positivas seriam herdadas, as causas de degeneração seguiriam o mesmo princípio, sendo as mais comuns a sífilis, o alcoolismo, a tuberculose, outras intoxicações produzidas pelos chamados vícios elegantes, as moléstias mentais e condições sociais e nutricionais precárias. Defende que as pessoas exercitassem sua inteligência e escolhessem o momento oportuno para a procriação, favorecendo o momento de maior vigor físico e intelectual, para transmitir tais caracteres aos seus descendentes.

No final do século XIX, as percepções dos médicos dos diferentes grupos (clínicos, higienistas e bacteriologistas) mantinham relações de tensão e oposição, divergindo acerca da interpretação dos sintomas, diagnóstico diferencial e contagiosidade das várias enfermidades, bem como em relação à terapêutica e prevalência de causas na determinação das epidemias (Benchimol, 1995). Apesar dos avanços da medicina em relação à propagação das doenças infecciosas, com conhecimentos em relação aos agentes transmissores, a teoria de transmissão das "taras hereditárias" ainda se fazia presente, especialmente nesse período em que a sífilis, a tuberculose e o alcoolismo eram considerados os responsáveis pela degeneração moral e social, pois os indivíduos já nasceriam com uma tendência para adquirir tais males transmitiriam essas taras a seus descendentes.

Neste sentido, a transmissão das taras seria responsável pela propagação e manutenção de uma descendência degenerada, fraca, com tendências à criminalidade, à promiscuidade, à fraqueza física e moral, prejudicando ou inviabilizando o projeto de salvação nacional. Dessa forma, o combate ao alcoolismo, à criminalidade e a doenças como sífilis, lepra e tuberculose continuava sendo uma prioridade entre os eugenistas brasileiros, evidenciando a preocupação com a transmissão de uma hereditariedade mórbida.

Guimarães Filho (1926), em sua tese intitulada Da hygiene mental e sua importancia em nosso meio, aborda a assistência aos alienados no estado de São Paulo, as causas da alienação mental e aspectos gerais relacionados à higiene mental. Sobre as causas e a transmissão das moléstias infecciosas, o autor já reconhece os conhecimentos da microbiologia, explicando que as moléstias eram causadas por seres vivos, reconhecíveis e passíveis de medida, que 
teriam como fonte os corpos de pessoas doentes, sendo transmitidos por meio das excreções do corpo doente para o corpo são, por via direta ou indireta. Apesar de evidenciar seus conhecimentos na área da microbiologia, a ideia da transmissão da "herança da degeneração" ainda se faz presente, por meio da defesa de que os indivíduos que procriassem durante o estado agudo de intoxicações ou infecções teriam maior probabilidade de transmitir aos seus descendentes os estigmas de sua degeneração, como no caso dos alcoólatras:

A sciencia tem provado que grande numero de degenerados não são filhos directos da degeneração de seus ascendentes, mas fructos de certos estados em que os paes se encontram no acto da procreação. Assim, individuos tarados e que procream em estado agudo de intoxicação ou de infecção, têm grande probabilidade para transmitir ao seu descendente os estigmas de sua degeneração, como acontece para os heredo-alcoolatras (Guimarães Filho, 1926, p. 147).

O termo estigma, de origem grega, originalmente refere-se a sinais corporais - como cortes ou marcas com fogo - usados para evidenciar características extraordinárias ou ruins sobre o status moral de quem o apresentasse, como escravos, criminosos ou traidores, indivíduos que deveriam ser evitados pelos demais membros da sociedade. A noção de estigma também é utilizada, de forma semelhante ao seu sentido original, para referir-se à desgraça em si, mais do que ao sinal corporal (Goffman, 1988). Nesse sentido, a noção de um estigma de degeneração transmitido hereditariamente para prole, em detrimento das descobertas no campo da microbiologia, está implicada com a construção de identidades sociais. Mais do que transmitir à descendência genes alterados, os indivíduos considerados indesejáveis propagariam uma tara mórbida, o estigma de uma identidade social e moral degenerada, que deveria ser repelida em prol da construção de uma raça eugenizada.
A associação entre eugenia, psiquiatria e medicina legal, que ocorreu com frequência em diferentes países da América Latina - inclusive no Brasil, no campo da higiene mental - contribuiu para a ampliação das justificativas supostamente científicas relacionadas a intervenções nas áreas de criminalidade, delinquência juvenil e prostituição, com direcionamentos marcadamente hereditaristas, a partir da teoria de transmissibilidade das taras, encontrando espaço nas faculdades de medicina a partir de 1920 (Kobayashi; Faria; Costa, 2009). A teoria do caráter hereditário do crime - proposta pelo médico italiano Cesare Lombroso no final do século XIX e bem aceita no meio científico pelos eugenistas - era baseada em dados antropométricos e reforçava a ideia de estigmas anatômicos em criminosos. Lombroso propunha que as características físicas e mentais de famosos criminosos se configuravam como tipos atávicos do ponto de vista evolutivo, que perdurariam se inseridos na sociedade civilizada, gerando comportamentos próprios de animais selvagens (Gould, 1991).

Em relação ao casamento, Ribas (1927) - em sua tese Exame pré-nupcial - afirma que esse exame deveria acontecer a partir da união de indivíduos hígidos ${ }^{8}$, considerando não apenas fatores individuais, mas, acima de tudo, os interesses da sociedade, da raça e da pátria, tendo a eugenia papel fundamental para guiar a escolha dos matrimônios. Aponta como principais doenças que poderiam ser transmitidas entre cônjuges as doenças venéreas, a tuberculose e a lepra. A respeito da lepra, apesar de já haver conhecimentos em microbiologia apontando para a não hereditariedade da doença, ainda se pregava alguma forma de contágio aos descendentes:

A lepra parece não ser molestia hereditaria como tambem não o é a tuberculose. Mas, como nesta, é provavel que aos filhos seja transmittido um estado especial de receptividade para a molestia que os autores denominam predisposição (Ribas, 1927, p. 31-32).

8 Consideravam-se “indivíduos hígidos” aqueles que não possuíssem doenças graves e transmissíveis, acometimentos de ordem física ou psíquica, bem como ausência de estigmas que se acreditava serem transmitidos para os descendentes. 
Ha uma força extranha cujo mechanismo de acção não está ainda sufficientemente explicado pela qual os filhos tendem a herdar dos seus progenitores tanto as bôas como as más qualidades. Desde os tempos biblicos encontramos referencias á-hereditariedade - como nós a chamamos hoje (Ribas, 1927, p. 35).

Monteleone (1929), em sua tese Os cinco problemas da eugenia brasileira, aponta como principal diferença entre animais e seres humanos a capacidade de tomar decisões racionais, justificando o uso da inteligência para guiar escolhas sexuais, casamentos eugênicos e procriação. Exalta a importância da aplicação das leis de Mendel sobre a hereditariedade de seres humanos, para justificar que "não devemos insistir porque é impatriotico. Os anormaes não têm direito á geração de typos anormaes" (Monteleone, 1929, p. 21):

o que se transmitte por hereditariedade de paes a filhos é a disposição morbida interna, o typo, a modalidade de unidade vital que torna o individuo apto a desenvolver esta ou aquella molestia [...] Os casamentos eugenicamente orientados concorrerão para diminuir e attenuar os vicios de familia, evitando a transmissão de disposições morbidas de paes a filhos e a procreação de entidades malformadas, degeneradas, inuteis á família e á patria (Monteleone, 1929, p. 28).

Os emergentes estudos na área de microbiologia do início do século XX surgiam como possíveis alternativas para a então vigente teoria da transmissibilidade das taras hereditárias, porém, ainda assim, o discurso dos autores das teses aqui analisadas indica que a força política e ideológica imbuída naquela teoria permitiu que cientistas e intelectuais continuassem defendendo medidas excludentes para os portadores do que era considerado no período como um sinal de degeneração.

\section{A eugenia mendelista impedindo a degeneração: exame pré-nupcial e esterilização eugênica}

Apontando para os riscos decorrentes da procriação de pais portadores de doenças mentais, sífilis e outras doenças venéreas, tuberculose e usuários de álcool, diferentes autores (Antunes, 1926; Bacellar, 1926; Godoy, 1927; Guimarães Filho, 1926; Monteleone, 1929; Ribas, 1927) defendem a instituição do exame pré-nupcial, impedindo a reprodução dos "degenerados", os indivíduos que apresentassem taras suscetíveis de serem transmitidas aos seus descendentes. 0 exame médico pré-nupcial seria uma das formas de implementar o controle dos casamentos nos casos de reprodução indesejada para a melhoria racial:

Quando se verifica que uma pessoa está em condições de gerar somente anormaes, debeis, doentes e degenerados, a sociedade terá direito de cassar-lhe as vantagens de uma união legitima, pois os interesses da raça estão em jogo. Seria uma protecção aos proprios degenerados do futuro que assim não chegariam a penetrar no scenario da vida para representar o seu triste papel (Antunes, 1926, p. 28).

Aos 2 sexos, quando se encontrem num estado de inferioridade de corpo ou de espirito, deveria ser interdicto o cazamento. Estas uniões fataes, aneugenicas, que são um atentado contra a familia e a sociedade, rezultam da ambição inconciente ou delinquente das classes ricas, das classes ditas dirigentes e da ignorancia relativa ás ciencias naturaes em geral e ao que concerne ao homem em particular [...] Um individuo com infecção gonococica, incapaz de bem procrear, caza-se livremente, legalmente" (Godoy, 1927, p. 40).

Elle [o exame pré-nupcial] se impõe em toda a parte, onde quer que haja homens e mulheres para a procreação de novas organizações humanas, novas civilizações, novos povos; povos fortes, não tarados, puros, sem heranças mórbidas e sãos mentalmente (Monteleone, 1929, p. 37).

Guimarães Filho (1926) defendeu que, para que a higiene mental fosse bem conduzida no seio familiar, deveria ser considerada a questão de sua constituição: "São os preceitos eugeneticos, que devem orientar a Hygiene na grande obra da melhoria da especie, pela prophylaxia mental" (Guimarães 
Filho, 1926, p. 145). Sendo assim, defende que o problema da loucura não poderia ser resolvido sem uma intervenção efetiva sobre os casamentos, envolvendo a questão da hereditariedade, sendo o exame pré-nupcial considerado fundamental nesta empreitada: "O exame pre-nupcial, que em nada ofende as susceptibilidades de cada um e o conhecimento de seus antepassados são os factores principaes para a prophylaxia, quer geral, quer mental" (Guimarães Filho, 1926, p. 148).

Bacellar (1926), em sua tese intitulada $A$ surdo mudez no Brasil, aponta como uma das principais medidas para a profilaxia da surdo-mudez congênita o exame pré-nupcial obrigatório, especialmente no que se refere à prevenção e ao combate à sífilis, uma das causas da surdez congênita. Reforça a necessidade da profilaxia e da propaganda eugênica para evitar a propagação das moléstias, assim como das taras que seriam transmitidas hereditariamente:

A regulamentação do casamento dos syphiliticos, dos tuberculosos e de todos os individuos portadores de taras ou molestias contagiosas, decorrentes desse exame pré-nupcial, seria não só um trabalho de prophilaxia da surdo mudez congenita, como também da prophilaxia social. Relembraremos, que nem sempre se herda a molestia, mas sempre se herda um terreno propicio ao seu desenvolvimento (Bacellar, 1926, p. 74).

Ribas (1927) exalta a existência de leis referentes ao exame médico pré-nupcial em países do exterior, impedindo ou regulamentando o casamento de indivíduos portadores de moléstias transmissíveis, evitando, assim, a geração de uma prole degenerada. O exame pré-nupcial é considerado pelo autor como o procedimento na área da eugenia mendelista mais humano e normalmente aceito. A respeito do alcoolismo - tido como uma das principais causas da degeneração da raça - o autor descreve uma situação presenciada por ele, para ilustrar a importância dos cuidados na escolha dos parceiros para evitar uma prole disgênica. Expondo sua própria experiência, imprime pessoalidade à escrita, tornando-a mais próxima do leitor, gerando maior identificação e credibilidade:
Conheci um casal, aliás abastado, cujo chefe era um alcoolatra incorrigivel. Deste matrimonio nasceram quatro filhos, dois casaes. 0 filho mais velho ha muito que falleceu de tuberculose. 0 mais joven, ainda vivo, é imbecil. Das duas filhas existentes a mais edosa é cachetica, neurasthenica; a irmã mais moça acha-se, presentemente, sob o dominio inexoravel da peste branca. Tudo é obra do alcool, que, não contente em inutilisar o individuo faz espelhar na progênie os estygmas da decadencia como um pecado original!... (Ribas, 1927, p. 47).

Os exames pré-nupciais ocuparam lugar de destaque nos movimentos eugênicos na América Latina, especialmente nas discussões sobre gênero, raça e identidade nacional. Apesar de poucas propostas terem sido legalizadas no Brasil, os esforços em favor da legalização do exame pré-nupcial contribuíram para a aproximação entre a campanha eugênica e a ciência jurídica, trazendo influências para a concepção da eugenia brasileira (Castañeda, 2003; Stepan, 2005). Acerca do exame médico pré-nupcial, a Lei brasileira sobre o casamento civil previa que os pais pudessem solicitar dos candidatos a cônjuge de seus filhos, uma certidão de saúde, por meio do Decreto-lei no 181 , de 24 de janeiro de 1890, que foi abolido com a criação do Código Civil, em 1917. O fato de a lei permitir a solicitação do exame, mas não obrigar sua realização, levanta críticas por parte de Godoy (1927), que defende veementemente a modificação de tal aspecto:

Art. 20. Os paes, tutores ou curadores dos menores ou interdictos poderão exigir do noivo ou da noiva de seu filho, pupillo ou curatelado, antes de consentir no casamento, certidão de vaccina e exame medico, attestando que não tem lesão, que ponha em perigo proximo a sua vida, nem soffre molestia incuravel ou transmissivel por contagio, ou herança (Brasil, 189oa).

E' tempo do governo brazileiro tornar obrigatorio, por lei, o exame pré-nupcial. E' tempo dos higienistas brazileiros cuidarem desse magno problema. E' tempo de ensinar e mesmo impor-se a selêção eugênica. Do contrario, em vez de homens fortes e inteligentes, vencendo a terra com máquinas poderozas sobre arranha-céos gigantescos, crecerá 
nesse Brazil nosso, uma confuza multidão de homens fracassados (Godoy, 1927, p. 51).

A defesa do exame médico pré-nupcial aparece nas teses doutorais como a medida mais recomendada para o controle de casamentos e outras vezes associada à esterilização. Como pesquisadores brasileiros favoráveis à esterilização, os principais são Francisco de Castro, Afrânio Peixoto, Renato Kehl e Paulo de Godoy, este último tendo publicado em 1927 sua tese doutoral pela Faculdade de Medicina e Cirurgia de São Paulo, já citada anteriormente.

Sampaio (1928), debruçou-se sobre o tema da esterilização eugênica em sua tese intitulada Esterilização eugenica e deontologia medica, apontando que o tema de estudo consistia em um dos pontos mais controversos e debatidos da questão eugênica, devendo ser confrontado segundo as diretrizes da deontologia médica e considerando questões de ordem moral e ética. Destaca que a esterilização para fins eugênicos provocava debates entre defensores e adversários desta prática, sendo indicada, em geral, nos casos em que "o individuo é portador de um caracter pathologico, cuja transmissão hereditaria é indiscutivel e em que a incurabilidade do defeito hereditario é tambem estabelecida" (Sampaio, 1928, p. 19).

As medidas de esterilização e confinamento tinham como alvo os grupos mais empobrecidos e miscigenados da população, a fim de impedir a reprodução dos indivíduos considerados "degenerados" e "medíocres". Tais medidas, propostas pelos defensores da eugenia negativa, geravam discussão e polêmica entre a sociedade e a intelectualidade brasileiras, tendo como opositores, principalmente, setores como a Igreja e alguns médicos mais conservadores, que rejeitavam o controle da natalidade devido a questões morais, religiosas e pelo temor do despovoamento do território brasileiro, o que prejudicaria a conquista de uma nação forte no país (Mai; Angerami, 2006; Mota, 2005).

Contrariando os segmentos que se opunham à esterilização, Godoy (1927) defende a prática como sendo uma técnica que não modifica, não perturba, nem desequilibra o organismo feminino e evita o uso de técnicas não seguras para impedir ou interromper a gestação, como introdução de objetos e substâncias químicas no órgão sexual feminino e abortos artificiais. Justifica a esterilização pelo fato de as taras mórbidas serem transmitidas dos pais a seus descendentes, mesmo sem a comprovação de um agente orgânico que fosse transmissível hereditariamente: "Todos os enfermos reconhecidamente capazes de transmitir outras graves e permanentes infecções á decendencia, têm de ser excluídos do direito de conceberem e procrearem. Como exemplo, temos os psicopatas sexuaes" (Godoy, 1927, p. 57):

A esterilização, dizem, estancando as fontes de reprodução, fére a nação nas suas nacentes vivas. Engano. Não se paralizam as fontes reprodutoras da especie pelo simples impedimento da multiplicação nefasta dos anómalos, dos decadentes, dos inviaveis. Os viciados são élos perdidos na cadeia das gerações. Pior ainda, são celulas de proliferação canceroza da humanidade, como bem disse Francisco de Castro (Godoy, 1927, p. 67).

A esterilização humana para fins eugénicos e raciaes não póde ser considerada absurda e impraticavel. Acoimar de impossivel essa inovação cientifica, significa a mais solêne capitulação, pela fraqueza, da Ciencia cujo culto professamos. Porque a ciencia é evoluir, transformar, melhorar. A rotina, inercia e involução, não a poderá fixar no tempo e no espaço (Godoy, 1927, p. 9o).

Monteleone (1929) apresenta seus posicionamentos acerca da esterilização eugênica de forma distinta, a depender do contexto considerado. Durante sua exposição acerca dos meios para evitar doenças como a sífilis e outras doenças venéreas, a tuberculose e os males da degeneração causados pelo uso de álcool, o autor defende com veemência o exame pré-nupcial como forma de garantir a procriação de indivíduos eugênicos. Porém, quando discorre sobre os males ocasionados pela lepra, expõe de forma explícita sua inclinação pelas medidas de esterilização. Assim como a tuberculose, a lepra também era considerada como uma das grandes ameaças à saúde da coletividade, a mais repugnante dentre as moléstias contagiosas, carregando os doentes o estigma de uma vida condenada ao isolamento e à marginalização: "Sou contra a esterilização. Mas para a lepra, não me envergonho de indicar a severa e 
immoral medida. Mais criminosa ainda será a actual sociedade se permittir, como ainda se faz no Brasil, o casamento de leprosos" (Monteleone, 1929, p. 68).

Maragliano Junior (1928), em sua tese Da syphilis congenita e sua prophylaxia: tratamento prenatal, aponta o combate à sífilis como essencial para o melhoramento da raça. Sobre a profilaxia antes do casamento, o autor cita a esterilização dos portadores de sífilis, que compreenderia também seu tratamento sistemático e o tratamento do futuro cônjuge, educando-o em relação aos riscos para sua descendência, impedindo o casamento até o término da fase infectante da doença:

Nos Centros [de Saúde] pode-se fazer seguramente $\mathrm{o}$ ataque a todos os factores responsaveis por esses accidentes. Em primeiro logar estão os procreadores. A esterilisação desses portadores de germens representa o primeiro passo na luta contra a syphilis. 0 tratamento prenatal, em segundo logar, assegura ainda mais os resultados (Maragliano Junior, 1928, p. 90).

Apesar de as discussões acerca da esterilização eugênica serem controversas e muitas vezes evitadas nos dias atuais, faz-se importante apontar que posicionamentos favoráveis a esta prática não aconteceram apenas nos Estados Unidos e em países europeus, sendo também defendidas em países latino-americanos, incluindo o Brasil, como é possível perceber no discurso dos autores analisados. A defesa de medidas eugênicas restritivas, como exame médico pré-nupcial e esterilização compulsória, pode ser encontrada nas teses doutorais apresentadas de forma robusta e contundente. A eugenia praticada no início do século XX, inclusive no Brasil, carregava um forte componente de disciplinamento pelo Estado, a partir de medidas autoritárias de controle e padronização dos corpos, com a finalidade de homogeneização da população, aprimoramento da raça e constituição de um povo cada vez mais apto ao trabalho e à produção econômica.

\section{Considerações finais}

Por meio das análises realizadas, é possível perceber que a eugenia mendelista, apesar de receber menos destaque nos estudos brasileiros, teve lugar nas discussões da intelectualidade nacional, transcendendo as divagações filosóficas e passando da teoria para a prática por meio do incentivo à promoção de eventos e premiações a indivíduos eugenizados, apoio e criação de decretos e leis acerca do exame médico pré-nupcial, assim como ampla divulgação de conhecimentos de ordem científica que justificavam, mesmo que implícita e cautelosamente, comportamentos discriminatórios e racistas, alguns dos quais se fazendo presentes até os dias atuais.

A criação da Sociedade Eugênica de São Paulo em 1918 - primeira do Brasil e da América Latina a fundação da Liga Paulista de Higiene Mental no início da década de 1920 - cujo principal objetivo era o saneamento da raça e a constituição de uma nação, agregando, para isso, teorias da higiene mental e da eugenia - a realização dos Congressos Brasileiros de Eugenia, a publicação e divulgação nacional do periódico Boletim de Eugenia, contando com a participação de reconhecidos médicos na autoria dos artigos, constituem exemplos do espaço político e institucional que a eugenia ganhava no território brasileiro, especialmente no meio médico paulista.

A proximidade entre Arnaldo Vieira de Carvalho e Renato Kehl, considerado o maior publicista da eugenia no Brasil e as interferências da Fundação Rockefeller na organização do curso de Medicina da faculdade em questão neste artigo - fundação esta que financiou laboratórios de pesquisa eugenista na Alemanha e nos Estados Unidos - bem como a materialização dos preceitos eugênicos divulgados à população a partir da premiação nos concursos de eugenia para as crianças consideradas eugenizadas, reforçam o importante papel dos médicos na implementação de tais medidas no contexto brasileiro. As leis brasileiras que permitiam medidas como o exame médico pré-nupcial e a restrição da entrada de imigrantes africanos e asiáticos também carregam influências do pensamento eugênico na sociedade brasileira.

Ainda que não tenham se constituído como práticas institucionalizadas no Brasil, a esterilização de indivíduos considerados disgênicos e a obrigatoriedade do exame pré-nupcial também foram encorajadas por diferentes intelectuais brasileiros, ganhando destaque nas publicações médicas em congressos 
científicos, livros, artigos de periódicos, passando pelas vias acadêmicas por meio da produção discente das teses doutorais, chanceladas pelos professores da faculdade de medicina, já constituídos como médicos respeitáveis. Mesmo não se configurando como documentos oficiais que norteassem as práticas eugênicas no país, as fontes aqui utilizadas representam ideais da grande elite de pensadores brasileiros, encabeçada pelos médicos, que, por sua vez, ocupavam também posições para além da medicina, com grandes influências na política e institucionalização de preceitos e recomendações à população geral.

Alinhadas ao contexto histórico em que foram produzidas, as fontes utilizadas nesta pesquisa permitem a compreensão das representações que a figura do médico alcançava no início do século XX, em uma posição de superioridade científica e de trânsito entre áreas para além da medicina, como o meio jurídico. Tais fontes consistem em vestígios relevantes de um passado que, apesar de reiteradamente negado em estudos atuais, fornecem subsídios para refletir sobre a importância das teorias e práticas no campo do saber médico e em saúde através dos tempos. Ao proporem intervenções em espaços que iam além das delimitações estritamente médicas, opinarem sobre a formulação de leis e reafirmarem definições pautadas em teorias já combatidas pela ciência, os escritos dos médicos demonstram não ser possível dissociar completamente suas práticas profissionais de suas ideologias pessoais, configurando-se como representações de um universo mais amplo de concepções da sociedade.

\section{Referências}

ANTUNES, P. C. A. Eugenia e immigração. 1926.

Tese (Doutorado em Medicina) - Faculdade de

Medicina da Universidade de São Paulo, São

Paulo, 1926.

BACELLAR, A. O. A surdo mudez no Brasil. 1926. Tese (Doutorado em Medicina) - Faculdade de

Medicina da Universidade de São Paulo, São

Paulo, 1926.

BARBOSA, P. Dicionário de terminologia médica portuguesa. Rio de Janeiro: Livraria Francisco

Alves, 1917.
BENCHIMOL, J. L. A institucionalização das ciências biomédicas no Brasil: esboço de um estudo comparativo. In: ALFONSO-GOLDFARB, A. M.; MAIA, C. A. História da ciência: o mapa do conhecimento. São Paulo: Edusp; Rio de Janeiro: Expressão e Cultura, 1995. p. 947-968.

BERTUCCI, L. M. Saúde: arma revolucionária: São Paulo, 1891/1925. Campinas: Centro de Memória Unicamp, 1997.

BERTUCCI, L. M. Sanear a raça pela educação: teses da Faculdade de Medicina e Cirurgia de São Paulo, início dos anos 1920. In: MOTA, A.; MARINHO, M. G. S. M. C. Eugenia e história: ciência, educação e regionalidades. São Paulo: Faculdade de Medicina da USP, 2013.

BLACK, E. A guerra contra os fracos: a eugenia e a campanha norte-americana para criar uma raça superior. São Paulo: A Girafa, 2003.

BONFIM, P. R.; KUHLMANN JUNIOR, M. Eugenia e Educação: uma leitura crítica do Boletim de Eugenia (1929-1933). In: ENCONTRO DE PESQUISA EM EDUCAÇÃO DA REGIÃO SUDESTE, 11., 2014, São João del-Rei. Anais... São João delRei: UFSJ, 2014, p. 1-10.

BRASIL. Decreto ${ }^{0} 181$, de 24 de janeiro de 1890. Promulga a lei sobre o casamento civil. Coleção das Leis do Império do Brasil, Brasília, DF, 189oa, v. 1, n. 1, p. 168. Disponível em: <https://goo.gl/ d1SBAL $>$. Acesso em: 26 jun. 2016.

BRASIL. Decreto $n^{\circ} 528$, de 28 de junho de 1890. Regulariza o serviço da introdução e localização de imigrantes na República dos Estados Unidos do Brasil. Coleção das Leis do Império do Brasil, Brasília, DF, 189ob, v. 1, n. 6, p. 1424. Disponível em: <https://goo.gl/RVffSd>. Acesso em: 17 jun. 2016.

CASTAÑEDA, L. A. Eugenia e casamento. História, Ciências, Saúde - Manguinhos. Rio de Janeiro, v. 10, n. 3, p. 901-930, 2003.

CHARTIER, R. O mundo como representação. Estudos Avançados, São Paulo, v. 11, n. 5, p. 173191, 1991. 
FOUCAULT, M. Microfísica do poder. Rio de Janeiro: Graal, 1984.

GALTON, F. A theory of heredity. The journal of the Anthropological Institute of Great Britain and Ireland, London, v. 5, p. 329-348, 1876. Disponível em: <https://goo.gl/ozK3Ts>. Acesso em: 22 jan. 2015 .

GODOY, P. Eugenia e seleção. 1927. Tese

(Doutorado em Medicina) - Faculdade de Medicina da Universidade de São Paulo, São Paulo, 1927.

GOFFMAN, E. Estigma: notas sobre a manipulação da identidade deteriorada. Rio de Janeiro: LTC, 1988.

GOULD, S. J. A falsa medida do homem. São Paulo: Martins Fontes, 1991.

GUIMARÃES FILHO, A. Da hygiene mental e sua importância em nosso meio. 1926. Tese (Doutorado em Medicina) - Faculdade de Medicina da Universidade de São Paulo, São Paulo, 1926.

KEHL, R. O nosso boletim: Instituto Brasileiro de Eugenia. In:_____., R. Boletim de Eugenia, Rio de Janeiro, v. 1, n. 1, 1929.

KEVLES, D. J. In the name of eugenics: genetics and the use of human heredity. New York: Knopf, 1985 .

KEVLES, D. J. Eugenics and human rights. British Medical Journal, London, v. 319, n. 7207, p. 435438, 1999.

KOBAYASHI, E.; FARIA L.; COSTA, M. C. Eugenia e Fundação Rockefeller no Brasil: a saúde como proposta de regeneração nacional. Sociologias, Porto Alegre, v. 11, n. 22, p. 314-351, 2009.

MAI, L. D.; ANGERAMI, E. L. S. A inserção do termo eugenia na Revista Brasileira de Enfermagem - REBEn, 1932 a 2002. Ciência, Cuidado e Saúde, Maringá, v. 5, p. 85-91, 2006. Suplemento.

MARAGLIANO JUNIOR, L. Da syphilis congenita e sua prophylaxia: tratamento prenatal. 1928. Tese (Doutorado em Medicina) - Faculdade de Medicina da Universidade de São Paulo, São Paulo, 1928.
MARINHO, M. G. S. M. C. Elites em negociação. Breve história dos acordos entre a Faculdade de Medicina de São Paulo e a Fundação Rockefeller (1916-1931). In: MOTA. A.; MARINHO, M. G. S. M. C. (Org.) Caminhos e trajetos da filantropia científica em São Paulo. A Fundação Rockefeller e suas articulações no ensino, pesquisa e assistência para a medicina e saúde (1916-1952). São Paulo: Faculdade de Medicina da USP, 2013. p. 79-175.

MARINHO, M. G. S. M. C.; MOTA, A. Da Faculdade de Medicina e Cirurgia de São Paulo à Faculdade de Medicina da Universidade de São Paulo: conjunturas e contextos. São Paulo: Faculdade de Medicina da Universidade de São Paulo, 2012.

MARQUES, V. R. B. A medicalização da raça: médicos, educadores e discurso eugênico. Campinas: Editora da Unicamp, 1994.

MONTELEONE, P. Cinco problemas da eugenia brasileira. São Paulo, 1929. Tese (Doutorado em Medicina) - Faculdade de Medicina da Universidade de São Paulo, São Paulo.

MOTA, A. Quem é bom já nasce feito: sanitarismo e eugenia no Brasil. Rio de Janeiro: DP\&A, 2003.

MOTA, A. Tropeços da medicina bandeirante: medicina paulista entre 1892-1920. São Paulo: Edusp, 2005.

MOTA, A. Quem tem medo da eugenia? Permanências discursivas de uma prática inacabada. In: MONTEIRO, Y. N., CARNEIRO, M. L. $\mathrm{T}$ (Org.). As doenças e os medos sociais. São Paulo: Fap-Unifesp, 2012. p. 219-249.

NOVAES, H. M. D. A puericultura em questão. In: MOTA, A.; SCHRAIBER, L.B. Infância e Saúde: perspectivas históricas. São Paulo: Hucitec, 2009. p. 121-170.

RIBAS, E. Exame pré-nupcial. 1927. Tese (Doutorado em Medicina) - Faculdade de Medicina da Universidade de São Paulo, São Paulo, 1927.

SAMPAIO, G. Esterilizacao eugenica e a deontologia medica. 1928. Tese (Graduação em Medicina) - Faculdade de Medicina da Universidade de São Paulo, São Paulo, 1928. 
SÃO PAULO (Estado). Decreto n ${ }^{0}$ 5·351, de 16 de janeiro de 1932. Reorganiza o ensino da Faculdade de Medicina de São Paulo. Diário Oficial do Estado de São Paulo, São Paulo, 17 jan. 1932. p. 1.

SÃO PAULO (Estado). Decreto $n^{0}$ 7.065, de 6 de abril de 1935. Aprova o regulamento da Faculdade de Medicina da Universidade de São Paulo. Diário Oficial do Estado de São Paulo, São Paulo, 19 maio 1935. p. 1.
SCHWARCZ, L. M. O espetáculo das raças: cientistas e questão racial no Brasil - 1870-1930. São Paulo: Companhia das Letras, 1993.

STEPAN, N. L. A hora da eugenia: raça, gênero e nação na América Latina. Rio de Janeiro: Fiocruz, 2005.

THOMPSON, E. P. A miséria da teoria ou um planetário de erros: uma crítica ao pensamento de Althusser. Rio de Janeiro: Zahar, 1981.

\section{Contribuição dos autores}

Verzolla e Mota foram responsáveis pela concepção do estudo, análise e interpretação dos dados e redação do artigo.

Recebido: 19/12/2016

Reapresentado: 20/05/2017

Aprovado: 18/07/2017 